\title{
Prevenção da dengue: a informação em foco
}

\author{
Dengue prevention: focus on information
}

\author{
Márcia de Freitas Lenzi ${ }^{1}$ e Lea Camillo Coura ${ }^{2}$
}

\begin{abstract}
RESUMO
O Estado do Rio de Janeiro viveu uma grande epidemia de dengue com um número expressivo de casos de Febre de Dengue Hemorrágica durante o primeiro trimestre do ano de 2002. Na ocasião, o poder público conclamou a participação da população nas ações de combate aos focos domésticos do vetor, na tentativa de controlar a situação. Para essa mobilização, uma grande gama de informações sobre a doença foi veiculada com intuito de esclarecer e orientar a sociedade. Neste trabalho, buscou-se analisar os conteúdos informativos dos materiais produzidos pelas campanhas de esclarecimento, focando a atenção nos três folhetos maciçamente distribuídos à época no município do Rio de Janeiro, considerando que essas informações contribuem para a construção da representação social da doença e sua prevenção. Pôde-se concluir que mesmo já tão repetidamente divulgadas essas informações precisam ser repensadas.
\end{abstract}

Palavras-chaves: Informação. Dengue. Prevenção. Campanha. Aedes aegypti. Controle.

\section{ABSTRACT though this information was provided repeatedly it must be revised. \\ SITUAÇÃO DA DENGUE NO RIO DE JANEIRO: UMA BREVE RETROSPECTIVA}

The first three months of 2002 witnessed a dengue epidemic in the State of Rio de Janeiro. At that time, health authorities encouraged community participation in the elimination of vector breeding sites. For this campaign, a great quantity of information about the disease was extensively publicized in order to guide the population's preventive action. This paper analyzed the three pamphlets most widely distributed at that time in Rio de Janeiro city considering that this information contributed to the construction of disease representation and its prevention. It was observed that even

Key-words: Information. Dengue. Prevention. Campaign. Aedes aegypti. Control.

A ocorrência da dengue em forma epidêmica já não pode ser considerada uma singularidade no Brasil. Desde 1986, vários estados brasileiros já conviveram com epidemias de grandes proporções. 0 número de casos de dengue notificados no país representa cerca de $80 \%$ do total de casos registrados nas Américas $^{15}$, e, de acordo com a Fundação Nacional de Saúde ${ }^{13}$, a distribuição da dengue pelo país, segundo os sorotipos circulantes até 2001 se apresenta conforme a Figura 1.

0 Estado do Rio de Janeiro tem um papel importante no quadro epidemiológico da dengue no Brasil, pelo fato de ser 0 primeiro Estado do país a registrar a circulação concomitante de 3 tipos de vírus: 1, 2 e 3 (DEN-1, DEN-2 e DEN-3), tendo consequentemente, uma alta taxa de incidência da doença e um grande número de casos registrados a cada epidemia ocorrida.

Numa breve retrospectiva, pode-se acompanhar a evolução das epidemias no estado desde 1986 a 2002, de acordo com os números oficiais divulgados: nos anos de 1986 e 87 com a introdução do DEN-1, foram notificados 93.910 casos. Em 1990 a identificação do DEN2 em Nova Iguaçu, desencadeou nova epidemia de grandes proporções, com o surgimento dos primeiros casos de dengue hemorrágica. No período de 1990/91 foram notificados 105.576 casos, sendo 1.316 de dengue hemorrágica (462 confirmados) e 8 óbitos9. Nos anos de 1995 e 1998, duas outras epidemias de menores proporções ocorreram, com 0 registro de 35.240 e 32.382 casos, respectivamente.

№ ano de 2000, foi identificado no Estado do Rio de Janeiro um caso de dengue tipo 3, e uma nova epidemia foi

\footnotetext{
1. Departamento de Ciências Sociais da Escola Nacional de Saúde Pública da Fundação Oswaldo Cruz, Rio de Janeiro, RJ. 2. Instituto de Pesquisa Clínica Evandro Chagas da Fundação Oswaldo Cruz, Rio de Janeiro, RJ.

Endereço para correspondência: Dra. Márcia de Freitas Lenzi. Dept ${ }^{0}$ de Ciências Sociais/ENSP/FIOCRUZ. R. Leopoldo Bulhões 1480, Manguinhos, 21041-210 Rio de Janeiro, RJ.

e-mail: mlenzi@ensp.fiocruz.br

Recebido para publicação em 24/4/2003

Aceito em 8/6/2004
} 


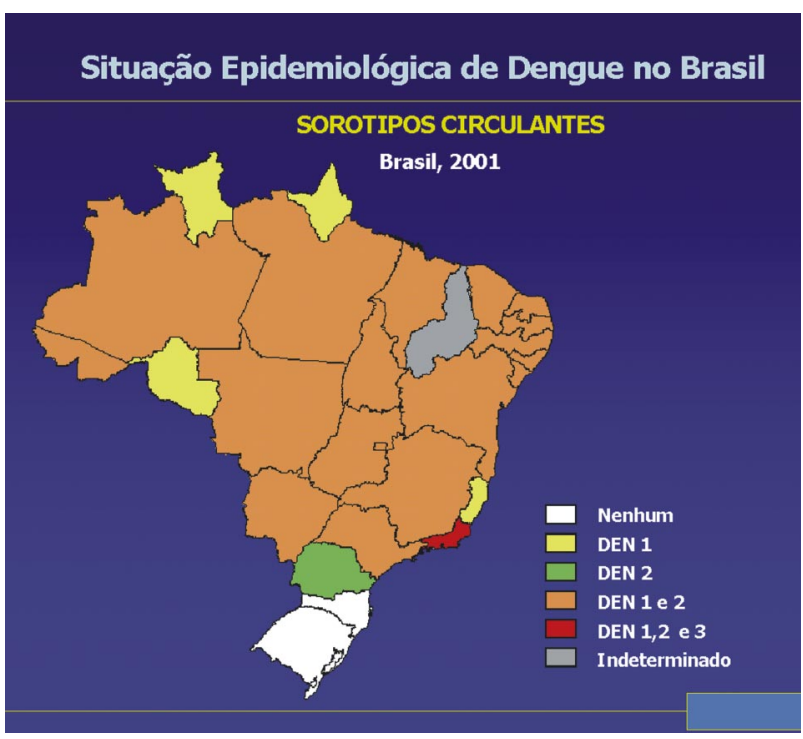

Figura 1 - Situação epidemiológica de dengue no Brasil. Fonte: FUNASA/Vigilância Epidemiológica.

prevista pelas autoridades da saúde. Em mais uma tentativa de controlar a grave ameaça de uma nova epidemia a nível nacional, a Fundação Nacional de Saúde/FUNASA lançou o Plano de Intensificação do Combate à Dengue em 2001, repassando uma verba extraordinária de R $\$ 115$ milhões aos estados para a capacitação de equipes e compra de equipamentos, além do lançamento de uma campanha de esclarecimento à população orçada em R\$20 milhões ${ }^{11}$.

Entretanto, no início do ano de 2002 o Estado do Rio foi aplacado com a mais grave epidemia desde então. Em apenas 3 meses foram notificados 166.393 casos, sendo 1.408 de dengue hemorrágica e 53 óbitos, segundo boletim epidemiológico divulgado pela Secretaria de Estado da Saúde à imprensa ${ }^{5}$.

Vale citar que o município do Rio de Janeiro, área mais afetada do Estado, teve registrados oficialmente no período 1986 a 2001, 0 total de 187.329 casos de dengue e 34 óbitos. Comparando-se esses números ao primeiro trimestre do ano de 2002, nota-se que a situação se agravou drasticamente com a circulação do novo sorotipo: foram 95.463 casos notificados no município ( $44 \%$ do total acumulado), sendo 571 de dengue hemorrágica e 31 mortes $^{16}$ numa população de aproximadamente 5.500 .000 pessoas as quais se sentem hoje ameaçadas por uma epidemia mais letal que as passadas. Cabe ressaltar que esses números são indicadores parciais, pois a não notificação dos casos é um fato que interfere diretamente nesse panorama.

Vários são os pontos críticos no controle dessa doença, tanto do ponto de vista biológico, ambiental, quanto do social e institucional.

Institucionalmente, por exemplo, os desafios são relacionados às atividades de vigilância; saneamento básico; inspeção e eliminação de reservatórios; e de informação, educação e comunicação (IEC) ${ }^{18}$.

Pelo fato de grande parte dos reservatórios, infestados ou potenciais, se encontrarem no interior dos domicílios ou ao seu redor, as atividades de IEC têm cada vez mais responsabilidades tanto no engajamento da população no controle dos focos do vetor, como no esclarecendo sobre o papel do poder público no combate à doença, permitindo que a população cobre intervenções eficazes neste sentido. 0 aumento do número de casos de dengue hemorrágica faz com que seja de fundamental importância a divulgação de sua sintomatologia de forma que contribua para 0 seu reconhecimento e pronto atendimento médico.

\section{A INFORMAÇÃO COMO UM IMPORTANTE INSTRUMENTO EM DEFESA À SAÚDE PÚBLICA}

Os materiais informativos produzidos e divulgados em uma campanha de saúde pública podem ter grande relevância no esclarecimento da população sobre a doença e sua prevenção, orientando sobre sintomas relativos a dengue clássica e a hemorrágica, além dos cuidados com focos domésticos, através da divulgação de informações científicas em linguagem popular, possibilitando a compreensão da etiologia, sintomatologia e medidas de controle.

Considerando a informação importante componente nos programas de promoção da saúde e prevenção de doenças, e que a dengue no país é um grave problema de saúde pública, mensagens informativas deveriam circular intensivamente durante todo 0 ano, evitando inclusive, a falsa idéia de que dengue só ocorre no verão.

Deve-se observar contudo, que campanhas de combate à dengue no Brasil não são de caráter permanente, tendo sua retomada e intensificação à época do verão - período de crescimento populacional do vetor. Já em 1991, Sabroza ${ }^{14}$ observou a redução das medidas de controle ocorrida após 0 pico da epidemia daquele ano: À medida que diminuiu a intensidade de transmissão da doença, e essa ficou limitada às áreas periféricas, onde as ações de controle são menores, diminuiu, também, a repercussão da doença na imprensa e a prioridade de seu controle.

Outro ponto negativo das campanhas contra a dengue que pode ser apontado ao se analisar os materiais impressos, é a limitação de informações sobre a dengue clássica e seus sintomas, e a inexistência de qualquer esclarecimento sobre dengue hemorrágica - quadro grave da doença, apesar de terem ocorrido vários casos desse tipo em 1991.

A informação que mais se observa nos materiais impressos se refere basicamente aos cuidados que se deve ter com os reservatórios mais prováveis de conter larvas do A aegypti. A título de ilustração, a seguir está apresentado os material impresso elaborado pelo Ministério da Saúde no ano de 2000 (Figura 2).

À essa época, o Estado do Rio de Janeiro estava vivendo um grande surto da doença. De acordo com o Ministério da Saúde, "para prevenir e conter a evolução do número de casos da doença era necessário mobilizar a população através da comunicação"; a campanha naquele ano, foi dirigida somente para a população do Estado do Rio de Janeiro.

No ano seguinte, em fevereiro de 2001, foi desenvolvido também pelo Ministério da Saúde, um outro material informativo em mais uma tentativa de mobilizar a população 


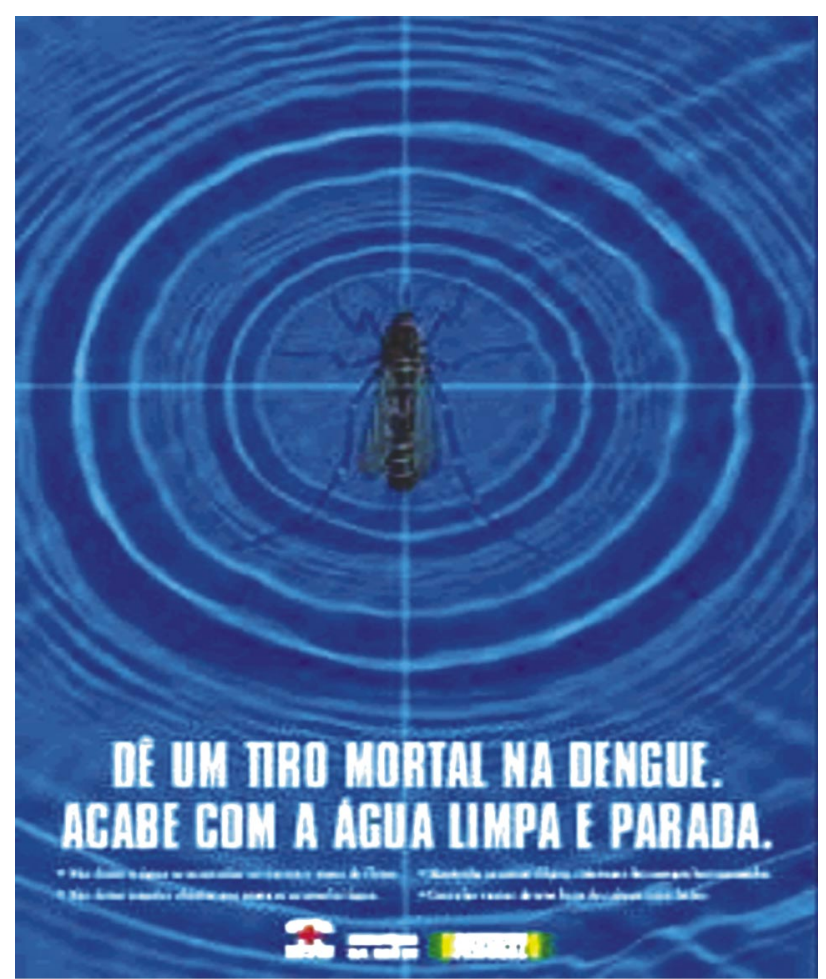

Figura 2 - Folheto elaborado em janeiro de 2000 pelo Ministério da Saúde. (frente).

e conter a evolução do número de casos da doença. A campanha ressaltou "a importância do papel da sociedade em ajudar a acabar com os focos do mosquito na sua casa tomando cuidados simples e eficazes". Essa campanha foi dirigida à toda população das áreas afetadas àquela época ( Rio de Janeiro, Espírito Santo, Rio Grande do Norte, Acre e São Paulo).

Refletir sobre a importância eadequação das informações sobre dengue divulgadas pelo órgãos oficiais junto à população é necessário, tendo em vista que essas informações podem contribuir para a defesa à saúde. Entretanto, reconhece-se que a relação entre conhecer e agir não é direta, condicionada e evidentemente decorrente. 0 indivíduo não é orientado exclusivamente pela lógica da escolha racional resultante de informações sobre comportamentos adequados que promoverão sua saúde. Seu agir é fruto de suas concepções, crenças e valores. Contudo, a não circulação de informações ou a circulação de informações de má qualidade podem levar à inação ou a ações ineficazes.

Apesar da participação da população ser considerada fundamental para 0 sucesso de qualquer campanha de saúde pública, é ainda muito pouco incentivada. Entretanto, em situações de maior gravidade, ela é convocada a agir. Um exemplo claro da necessidade da participação efetiva da população no combate à dengue ocorreu no início do ano de 2002, quando, devido a necessidade de se diminuir rapidamentea intensidade da epidemia que atingiu o Rio de Janeiro, foi programado pelo Ministério da Saúde em conjunto com as Secretarias de Saúde Estadual e Municipais, um evento para promover a mobilização de todos os setores da sociedade: 0 Dia D - 0 Rio contra a Dengue.

Para esse fim, foram utilizados todos recursos comunicacionais posśiveis que pudessem orientar a população em suas ações contra o mosquito transmissor: TV, jornais, rádio, cartazes, faixas, out- doors, peças teatrais, músicas e folhetos distribuídos por toda a cidade, através de agentes de saúde, voluntários e carteiros da Empresa Brasileira de Correios e Telégrafos. Mutirões para a limpeza das ruas e casas visando a eliminação de focos também foram organizados. 0 programa de controle foi intensificado por soldados do exército e marinha - treinados pela FUNASA nas inspeções domiciliares.

Pode-se considerar que a campanha conseguiu a atenção e adesão da população, amedrontada com a velocidade do surgimento de casos graves e óbitos, mas, apesar do grande investimento, a população ainda mostrava ter muitas dúvidas sobre a doença e se sentia despreparada para enfrentar a epidemia. A desinformação foi percebida pairando sobre todas as classes sociais. Esse fato chegou até às páginas dos jornais, tornando ainda mais evidente a necessidade de reflexão sobre a qualidade do trabalho de esclarecimento realizado:

Carioca ainda tem dúvidas sobre dengue [JBONLINE, 25/MAR/2002] ${ }^{6}$

Mesmo com a intensificação das campanhas educativas, pelo menos $30 \%$ da população do Rio ainda têm dúvidas sobre como evitar que suas casas sejam transformadas em focos do mosquito da dengue. A estimativa é da Defesa Civil municipal, que junto com os agentes da prefeitura tem vistoriado imóveis na cidade. "A desinformação ainda é grande, principalmente nas comunidades carentes", diz o capitão Edmundo Braga, diretor do órgão. Nas vistorias os agentes distribuem folhetos educativos a moradores.

Desinformação agrava epidemia[JBONLNE, 18/02/2002]

Eliana Caruso, 51, critica o descaso com que a doença tem sido tratada. "Até eu e meu irmão Edilberto, que somos professores, fomos vítimas da desinformação." Edilberto de Oliveira, 60, estava com dengue quando morreu de infarto no Sábado.

Apesar da grande ênfase dada ao assunto pela mídia, a avalanche de informações sobre diferentes tipos de cuidados com criadouros do mosquito e a falta de precisão acerca dos condicionantes e sintomas da dengue clássica e hemorrágica, dificultaram a orientação da população. Cabe ressaltar que, existem também crenças acerca da doença e apropriações das informações circulantes, que interferem de diferentes maneiras nas ações de prevenção e controle que precisam ser estudadas e consideradas para 0 desenvolvimento de materiais mais próximos à realidade social.

\section{ALGUNS EXEMPLOS DE MATERIAIS INFORMATIVOS ELABORADOS NA CAMPANHA "0 RIO CONTRA A DENGUE"I 2002}

Ainformação em saúde é uma estratégia de intervenção que ainda se encontra distante da realidade social definida pelas experiências cotidianas, representações e apropriações. Uma maior aproximação do campo científico ao senso comum se faz necessário para a interação entre essas formas de conhecimento, permitindo a construção de mensagens mais direcionadas e, 
possivelmente, de maior contribuição ao esclarecimento da população.

Partindo desse pressuposto, a análise dos conteúdos das informações contidas nos materiais da campanha de combate à dengue aqui apresentada, deve ser entendida como uma tentativa neste sentido.

As informações selecionadas para este estudo foram elaboradas pelos órgãos públicos de saúde, mais precisamente o Ministério da Saúde, Secretaria Estadual e Prefeitura.

Como em outras campanhas, uma maior ênfase foi dada aos tipos de reservatórios que servem à procriação do $\mathrm{A}$ aegypti, devido à maior complexidade no que se refere à sua eliminação ou controle, já que a maioria deles se localiza no interior dos domicílios, ficando sujeitos aos cuidados de seus moradores, que foram convocados a entrar na "guerra contra a dengue". Para esse fim ressaltou-se a necessidade da participação da população no cuidado com a casa, usando slogans do tipo: "Dengue: acabe com esse perigo na sua casa" ou "Dengue: o problema é de todos, a solução também".

A Figura 3 reproduz a mensagem produzida pela Secretaria Estadual de Saúde, distribuída em cartazes e outdoors pela cidade do Rio.

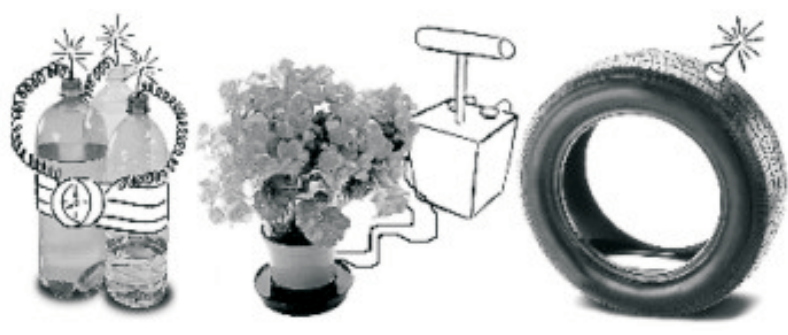

Figura 3 - Cartaz "Dengue: entre nessa guerra!".

Reforçando a campanha, várias reportagens foram divulgadas em rádios e jornais, com pareceres de especialistas enfatizando práticas preventivas alternativas como a utilização de velas de citronela e repelentes para evitar a aproximação do mosquito; borra de café, água sanitária, sal ou areia em lugares que acumulem água, principalmente, em pratos de planta.

Entre os materiais elaborados, os folhetos mereceram atenção especial neste estudo, devido a sua ampla distribuição e proposta de alcançar todos os grupos sociais independentemente do nivel sócio-cultural, orientando a população quanto aos cuidados necessários à prevenção da doença.

Para fins de discussão, foram escolhidos para análise de conteúdo os folhetos mais divulgados durante a campanha (Figura 4), apontando alguns aspectos positivos e negativos, visando uma futura avaliação desse material junto à população, principalmente a de baixa renda e escolaridade que representa um grande contingente nos grandes centros urbanos.

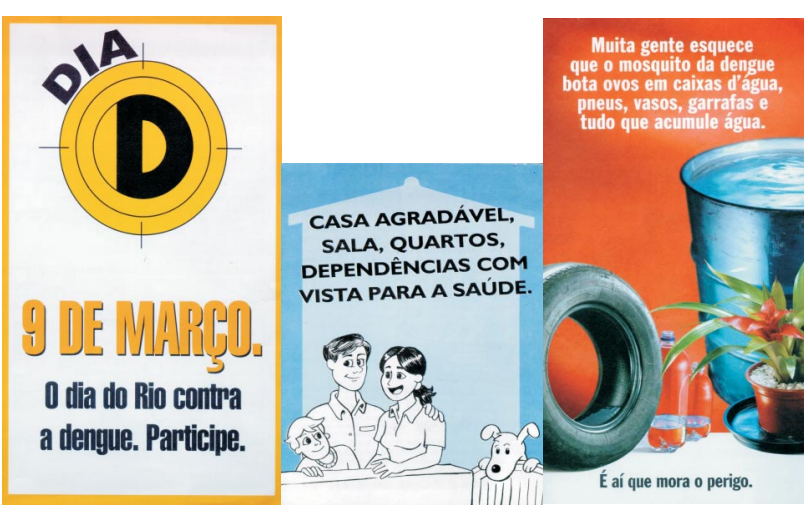

Figura 4 - Folhetos distribuídos na cidade do Rio de Janeiro, 2002.

Folheto 1: "Dia D 9 de Março. 0 dia do Rio contra a dengue. Participe."

Check-list elaborada pelo Ministério da Saúde em conjunto com a Secretaria Estadual e Prefeituras, consta exclusivamente de uma lista de procedimentos que orientam a inspeção, limpeza e eliminação de potenciais focos do vetor nas residências, sem abordar as questões sobre sintomatologia da denque clássica e hemorrágica e tratamento. As informações nã̃o são acompanhadas de nenhuma ilustração. Este folheto foi 0 mais divulgado entre a população, com distribuição pela Empresa Brasileira de Correios e Telégrafos em todo o Estado.

Folheto 2: "Casa Agradável, sala, quartos, dependências com vista para a saúde." Elaborado em parceria pela Fundação Nacional da Saúde/FUNASA e Secretaria Estadual de Saúde e distribuído em locais estratégicos, como escolas, clubes, shoppings e redes de mercados. Na parte interna, há ilustrações de três ambientes (casa, quintal e bairro) apontando hábitos ideais para evitar a reprodução do mosquito, ressaltando a participação de cada membro da família no cuidado em relação aos principais focos de A. aegypti. Na parte externa, há também textos informativos sobre 0 vetor, sintomas do dengue clássica e tratamento.

Folheto 3: "Muita gente esquece que o mosquito da dengue bota ovos em caixas d'água, pneus, vasos, garrafas e tudo que acumule água. É aí que mora o perigo."

Elaborado pelo Ministério da Saúde e distribuído durante a campanha em lugares

de grande concentração de pessoas como escolas, clubes, estações rodoviárias e metroviárias. Em seu interior existem reprodução ampliada do vetor, explicações sobre aloumas medidas preventivas relativas aos principais focos domesticos acompanhadas de ilustrações, alem de uma breve descrição da sintomatologia do dengue clássica.

\section{CONSIDERAÇÕES SOBRE CONTEÚDO DAS MENSAGENS DIVULGADAS:}

Relativos aos cuidados com os reservatórios. Observase que os três folhetos enfatizam as medidas preventivas voltadas aos cuidados com os reservatórios domésticos de maior importância epidemiológica na reprodução do vetor.

Em relação aos reservatórios de grande e médio porte que armazenam água, tais como caixas d'água, tonéis, cisternas e poços, os três folhetos orientam a população no sentido de mantê-los tampados. Essa informação é considerada inadequada quanto a utilização do verbo tampar, cuja interpretação pode favorecer situações como a observada na Figura 5. 


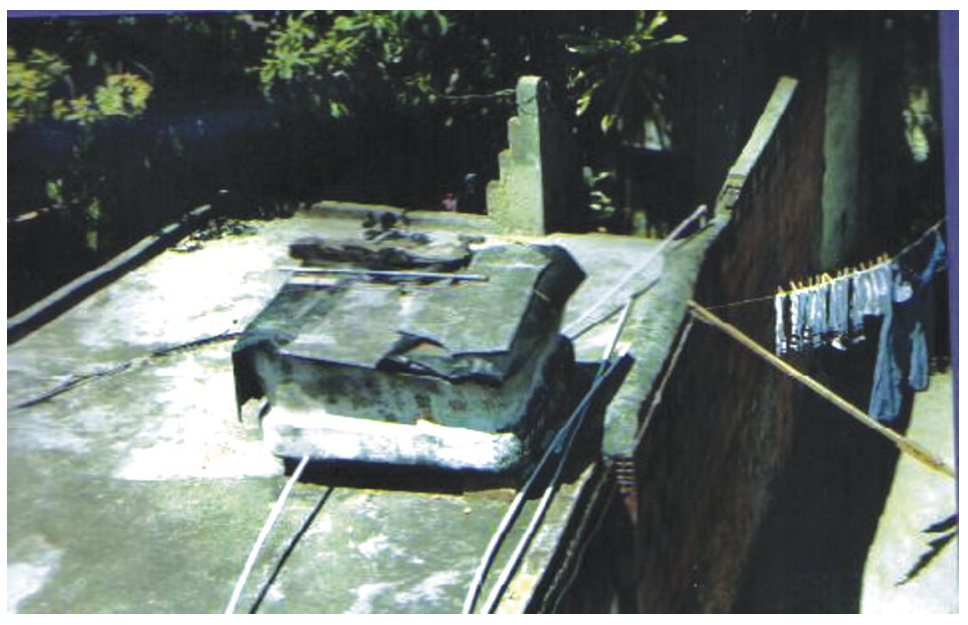

Figura 5 - Caixa d'água localizada sobre a laje.

0 mais adequado para esta situação seria 0 emprego do verbo vedar ou da expressão tampar sem deixar nenhuma brecha.

Ainda sobre esses tipos de reservatórios, 0 folheto 1 sugere como prática preventiva alternativa à tampa, 0 uso de tela tal como foi feito na campanha de 1928/29 no Estado do Rio de Janeiro ${ }^{8}$. Entretanto, não define 0 tipo de tela, que, para impedir a passagem do mosquito, necessita ter uma trama bem fechada. Para isso, a população teria que saber que 0 mosquito mede de $5 \mathrm{a} 7 \mathrm{~mm}$, e esta informação não consta em nenhum dos materiais divulgados.

Em relação aos pratos de plantas que são freqüentemente encontrados com acúmulo de água e presença de larvas do A. aegypti, observa-se diferentes abordagens no tratamento desse recipiente nos folhetos analisados. 0 folheto 1 é 0 mais preciso quanto a forma mais adequada de evitar a procriação do vetor, orientando para a colocação de areia até a borda do pratinho. Já os folhetos 2 e 3 propõem a lavagem dos pratos com escova ou pano semanalmente, para mantê-los livres dos ovos de mosquito. Essa medida é menos prática, pois necessita ser repetida com frequência, podendo incorrer no esquecimento ou negligência.

No tocante aos recipientes de pequeno porte, como copos descartáveis, latas, potes, ou quaisquer objetos que possam acumular água, recomenda-se no folheto 1 que se coloque tudo em saco plástico, feche bem ejogue no lixo, e ainda, Entulhos e lixo: não os acumule. Mantenha o quintal sempre limpo; já 0 folheto 2 recomenda que as latas devem ser furadas antes de ser jogadas fora para não acumular água, e ainda, o lixo caseiro deve estar ensacado e posto à disposição da limpeza urbana .

0 cuidado com a limpeza da casa, não acumulando objetos que armazenem água principalmente em quintais, é ressaltado nos dois folhetos mais amplamente divulgados à população ( 1 e 2). Entretanto, deve-se considerar que 0 conceito de limpeza assim como a classificação de lixo, são relativos, isto é, dependentes da relação que se dá entre signo e significado.

A definição literária da palavra lixo é aquilo que se varre da casa, do jardim, da rua e se joga fora; tudo o que não presta e se joga fora; coisa ou coisas inúteis, velhas, sem valor ( Novo Dicionário da Língua Portuguesa). Entretanto, para a população de baixa renda, as latas e potes podem ser considerados úteis e até fonte de renda. Frente ao fato, é importante a existência de propostas alternativas quanto a formas de armazenar esses tipos de recipientes, se necessário, tais como furá-los, ou guardá-los em sacos plásticos fechados ou guardálos virados para baixo.

Referindo-se às garrafas vazias, os folhetos $2 \mathrm{e} 3$ recomendam que aquelas reaproveitadas devam ser guardadas viradas para baixo; já 0 folheto 1 orienta apenas que jogue fora todas as que não usar, não acrescentando alternativas de armazenamento para aquelas não descartadas. Chama-se atenção para 0 fato que em nenhum dos três folhetos consta a orientação sobre a forma correta de armazenar as garrafas pet (de plástico) - atualmente muito mais freqüentes que as de vidro - mantendoas tampadas para evitar acúmulo de água.

Deve-se salientar contudo que é de extrema importância que o serviço público de coleta de lixo seja regular para que, em consonância com as recomendações sobre tratamento do lixo doméstico, a solução para esse problema seja eficiente.

Constam também nos folhetos, instruções referentes ao tratamento de outros tipos de recipientes, como pneus, baldes, jarras de flores, bebedouros de animais, bromélias e outros. Dentre esses, as bromélias mereceram maior atenção nessa campanha, já que há algum tempo, vem-se notando a utilização freqüente dessa planta para fins decorativos em prédios e casas. Segundo Forattini ${ }^{3}$, trata-se de um processo de domesticação resultando conseqüentes problemas de saúde pública, sendo este mais um traço cultural adquirido pela população. Este reservatório natural acumula água em seu interior (denominado como tanque), possibilitando o desenvolvimento de formas imaturas do A aegypti.

Atualmente, as bromélias não são relevantes na multiplicação do vetor, porém a ênfase dada em relação aos cuidados com a planta e até mesmo à sua eliminação, pode ter como justificativa 0 desenvolvimento na década de 80, do hábito de cultivar plantas em água descrito por Lima e cols ${ }^{8}$ como um elemento que, ao se generalizar, mudou a situação dos focos de A. aegypti no Rio de Janeiro. 
Dentre os materiais avaliados, somente 0 folheto 1 se refere aos cuidados com as bromélias ou outras plantas que possam acumular água, orientando para sua eliminação ou, no caso de mantê-las, tratar com água sanitária na proporção de uma colher de sopa para um litro de água, regando, no mínimo duas vezes por semana, tirando sempre a água acumulada nas folhas.

Vale ressaltar que na maioria das vezes, essa planta é utilizada mais freqüentemente em jardins, plantada diretamente na terra, dificultando a retirada da água acumulada nas folhas. Recomenda-se portanto que a orientação seja mais objetiva, voltada para 0 uso de produtos inseticidas ecológicos já testados e aprovados como a melhor forma de agir quanto ao controle de focos.

Relativos aos sintomas de dengue clássico e hemorrágica. Outras informações são tão relevantes quanto as que visam impedir a procriação do vetor e deveriam ser amplamente divulgadas, tais como: 0 que é dengue hemorrágica; qual a sintomatologia; como proceder no caso de adoecimento; que fatores de risco colaboram para 0 agravamento do quadro clínico (idade, hipertensão arterial, efisema pulmonar, diabetes, dentre outros), e outras informações que possam contribuir para a busca de atendimento médico imediato.

Pode-se observar que a descrição dos sintomas da dengue clássica não consta em todos os materiais informativos. Os folhetos 2 e 3 apresentam diferentes descrições, transcritas abaixo, enquanto 0 folheto 1 não aborda 0 assunto:

Folheto 2: Dores de cabeça, nas articulações, fraqueza, falta de apetite, febre e, em alguns casos, manchas avermelhadas na pele.

Folheto 3: Fique atento a dores de cabeça, nos músculos, nas juntas, nos olhos, além de febre alta por, no máximo, uma semana e manchas vermelhas por todo 0 corpo. Ao menor sinal, procure orientação em um posto de saúde.

Sobre a manifestação da forma grave, 0 folheto 2 alerta:

"Ela (a doença) pode se manifestar de forma branda ou grave. Na forma mais grave, há manifestações hemorrágicas intensas que podem levar à morte." (grifo original).

0 folheto 3 destaca, em fundo vermelho:

"Tem gente que acha que a dengue é uma doença qualquer. Mas esse é um engano que pode ser fatal. A dengue hemorrágica é muito grave e pode mesmo matar."

Analisando 0 conteúdo informativo, essas mensagens não trazem nenhuma contribuição no sentido de auxiliar a população no reconhecimento de sintomas básicos da dengue hemorrágica e da síndrome de choque da dengue. Ajudam, por outro lado, na formação da representação errônea de um quadro de hemorragia, com perda de grande quantidade de sangue, prejudicando a percepção da população a cerca dos sinais que alertam para a necessidade de tratamento médico urgente.

Com 0 aumento de número de casos de dengue hemorrágica, os materiaisinformativos necessitariam divulgar a sintomatologiade forma mais contundente, porém, durante a epidemia de 2002, esse esclarecimento ficou a cargo da mídia que divulgou pareceres de médicos e autoridades do campo da saúde, sem ter sido suficiente no esclarecimento da população.

Sugere-se que constem de todos os folhetos sobre dengue, descrições claras com linguagem simples, a exemplo da elaborada pelo Centro de Informação em Saúde para Viajantes/CIVES².

"É absolutamente necessário estar atento para as manifestações que podem indicar gravidade, 0 que pode acontecer, geralmente, a partir do momento em que a febre começa a ceder:

dor constante abaixo das costelas, do lado direito ( fígado).

- suores frios por tempo prolongado, tonteiras ou desmaios ( pressão baixa).

pele fria e pegajosa por tempo prolongado (pressão muito baixa).

- sangramentos que não param.

- fezes escuras como borra de café ( sangramento intestinal)."

Relativos ao tratamento. Não existe nenhum tratamento específico para dengue clássica. É recomendável repouso e ingestão abundante de líquido. 0 tratamento é referente aos sintomas. Para dores e febre, deve-se evitar a ingestão de medicamentos compostos por ácido acetil salicílico (AAS) , que têm ação anticoagulante.

Uma questão importante relativa ao tratamento dos sintomas da dengue é banalização do uso de paracetamol. Nenhum material divulga 0 perigo da ingestão de altas dosagens, que podem acarretar graves problemas de saúde. Muitos são os doentes que se tratam sem orientação médica, simplesmente por "já saberem o que fazer" sem conhecer o perigo da automedicação.

Os folhetos 2 e 3 recomendam a população a procurar um posto de saúde aos primeiros sintomas. Somente 0 folheto 2 alerta para 0 perigo de usar remédios à base de ácido acetilsalicílico "como a Aspirina, o AAS, entre outros, porque favorece o sangramento", e recomenda ao doente "ficar em repouso, beber muito líquido e só usar medicamentos para aliviar dores e febre", sem mencionar que a dosagem não deve ser maior que aquela recomendada pelo médico.

Relativos ao vetor e transmissão da dengue. 0 folheto 2 é 0 único material que contem informações sobre 
0 vetor, descrevendo sua reprodução, características e forma de transmissão:

Para sua reprodução, a fêmea se alimenta de sangue e é através de sua picada que 0 vírus é transmitido de uma pessoa contaminada à outra. 0 mosquito é parecido com 0 pernilongo, mas possui listras brancas em seu corpo, pica durante 0 dia e coloca seus ovos em recipientes com água limpa e parada. Estes ovos podem, no entanto, resistir até aproximadamente seis meses nas paredes secas dos recipientes, até que tenha contato com a água e se transforme em mosquito. Portanto, procure cuidar para que seus ambientes (casa, escola, trabalho, bairro) estejam sempre saudáveis e livres dos mosquitos.

É uma doença transmitida apenas pelo mosquito $\mathrm{A}$. aegypti; não é contagiosa de pessoa para pessoa. Ela pode se manifestar de forma branda ou grave. Na forma mais grave, há manifestações hemorrágicas intensas que podem levar à morte.

Uma dúvida muito freqüente da população nessa última epidemia, foi relativa aos condicionantes da dengue hemorrágica. Nenhum folheto contém essas informações, entretanto, os meios de comunicação de massa divulgaram pareceres de autoridades em saúde, baseados, em sua maioria, na teoria imunológica de Halstead ${ }^{4}$, sem relacioná-la a outros fatores (individuais e virais) considerados de risco para o seu desenvolvimento.

A falta de informação gerou uma grande insegurança na população, que observou a ocorrência da dengue na forma hemorrágica já na primeira infecção. É preciso que 0 acesso a essas informações também seja assegurado, de forma simples e clara para ser compreendida pelo maior número de pessoas possivivel, fato que pode contribuir para uma prevenção mais efetiva.

\section{COMENTÁRIOS FINAIS}

Em nível de planejamento, os componentes de informação, comunicação e educação (IEC) precisam ser melhor utilizados a partir de uma horizontalização dessa ação, mudando 0 caráter campanhista que ainda predomina no campo da saúde. Ainclusão de grupos sociais organizados na discussão de o quê e como informar, acresceria na qualidade da campanha. É importante sempre levar em conta que muitos moradores de áreas carentes da cidade do Rio de Janeiro são semi analfabetos, e por isso têm grande dificuldade quanto a leitura de folhetos, principalmente aqueles sem nenhuma ilustração.

Quanto a periodicidade da divulgação das informações sobre dengue, é fundamental que esta se dê permanentemente, pondo fim ao hiato de tempo existente entre um e outro verão. Ao baixar os níveis de infestação do mosquito e, conseqüentemente, da taxa de incidência da dengue, a circulação de informações sobre a doença é interrompida, e o trabalho de controle de focos passa a assumir uma freqüência e cobertura bem menores. Esse silêncio sazonal propicia um relaxamento quanto aos cuidados relativos aos reservatórios de importância epidemiológica.

Observa-se também, a necessidade de uma maior abrangência quanto aos tópicos abordados nas campanhas. Mesmo essas informações já tão repetidamente divulgadas precisam ser repensadas, tanto no que concerne ao conteúdo quanto a forma de serem divulgadas.

Informações relacionadas à sintomatologia da dengue clássica e hemorrágica precisam constar em todos os materiais informativos de forma destacada e concisa, com linguagem simples e esclarecedora, com vistas a ajudar a população na procura imediata de auxílio médico, evitando agravamento do quadro e, até mesmo, óbitos.

Outro aspecto muito importante é relacionado a automedicação, que leva em alguns casos, à ingestão de grandes doses de paracetamol devido ao grande desconforto causado pela doença. Não há informação sobre as consequiências no caso de uma super dosagem em nenhum material de campanha.

Os materiais informativos têm uma grande responsabilidade na orientação das ações preventivas junto à população. Por isso, é importante que elas venham de encontro aos problemas cotidianos, e que nesses materiais se encontrem respostas às dúvidas mais freqüentes, de forma correta e precisa. Para tal, os termos empregados e orientações dadas têm que estar norteados por essa premissa, 0 que evitaria situações como àquelas relativas ao tipo de tela para cobrir reservatórios que armazenem água, ao termo tampar as caixas d'água, dentre outras.

Seria importante que a dengue estivesse na pauta da mídia durante todo 0 ano como uma prestação de serviço à população, assim seria possível informar sobre práticas preventivas e também sobre condicionantes e sintomatologia da dengue de forma gradual e pedagógica.

As instituições de ensino também têm grande contribuição a dar na formação de jovens com vistas à promoção da saúde, tornando-os agentes sociais importantes em suas comunidades. Doenças endêmicas e/ou epidêmicas precisam ser abordadas de maneira consistente, interdisciplinar, criativa e adequada às realidades locais.

É fundamental frisar que a campanha de combate à dengue primeiramente requer a efetiva participação do setor público, responsável pelo saneamento básico e abastecimento de água, principalmente junto às áreas urbanas menos favorecidas dando condições mínimas à população para se prevenir contra várias doenças.

Não é impossível controlar os níveis de infestação do A aegypti em nosso território, de forma a reduzir ao mínimo a circulação da dengue. Precisamos para isso, que o governo faça a sua parte e que a sociedade seja, de fato, considerada aliada, e para tal, precisa ser respeitada e bem informada para que possa exercer seu papel, controlando e colaborando com o processo em toda a sua extensão.

\section{AGRADECIMENTOS}

Ao Dr. Carlos E.A. Coimbra Jr e à Dra. Keyla B.F. Marzochi pelo constante apoio. À Fundação Oswaldo Cruz pelo apoio financeiro através do Programa Desenvolvimento Tecnológico em Saúde Pública/PDTSP 


\section{REFERÊNCIAS BIBLIOGRÁFICAS}

1. Casos de Dengue por Mês e Evolução. http://www.rio.rj.gov.br/saude/ pubsms/media/DENG2002_50.doc, acessado em 12/4/2002.

2. Centro de Informação em Saúde para Viajantes (Cives), Universidade Federal do Rio de Janeiro. Texto Informativo em Dengue. http://www.cives.ufrj.br/ informacao/dengue/den-iv.html acessado em 03/02/2002.

3. Forattini OP, Marques GRAM. Finding of Aedes aegypti breeding in bromeliad. Revista de Saúde Pública 34: 543-544, 2000.

4. Halstead SB. Epidemiology of dengue and dengue hemorrhagic fever. In: Gubler DJ, Kuno G (eds) Dengue and dengue hemorrhagic fever, CAB International, New York, p.23-44, 1997.

5. Jornal do Brasil on line - Os números da epidemia. http://jbonline.com.br/ jb/papel/dengue/2002/04/12.html, acessado em 07/5/2002.

6. Jornal do Brasil on line-Carioca ainda tem dúvidas. http://jbonline.terra.com.br/ papel/dengue/2002/03/25.html, acessado em 26/03/2002.

7. Jornal do Brasil on line. Desinformação agrava epidemia. http:// jbonline.terra.com.br/papel/cidade/2002/02/18/jorcid20020218001.html, acessado em 19/02/2002.

8. Lima MM, Aragão MB, Amaral MB. Criadouros de Aedes aegypti encontrados em alguns bairros do Rio de Janeiro, 1984-85. Cadernos de Saúde Pública 4:293-300, 1988.

9. Ministério da Saúde, Fundação Nacional de Saúde, Boletim Epidemiológico, Ed. especial - Evolução Temporal das Doenças de Notificação Compulsória no Brasil de 1980 a 1998. Ano III, 1999.
10. Ministério da Saúde, Fundação Nacional de Saúde. Guia de Vigilância Epidemiológica, Dengue, Capítulo 5.4, 4ª edição, 10 páginas, 2000.

11. Ministério da Saúde, Fundação Nacional de Saúde, Plano de Intensificação do Combate ao Dengue, Julho/2001.

12. Ministério da Saúde, Fundação Nacional de Saúde, Boletim Epidemiológico, Ano1, N02, http://www.funasa.gov.br/pub/boletim_eletronico_epi/ boletim_eletronico_epi_0201.pdf acessado em 10/11/2001.

13. Ministério da Saúde, Fundação Nacional de Saúde, Vigilância Epidemiológica. Banco de Imagens, Parte 1: Material para Capacitação de Agentes do PACS/PSF nas Ações de Controle da Dengue. http:// www.funasa.gov.br/epi/dengue/dengue1.htm acessado em 18/3/2002.

14. Sabroza PC, Toledo LM, Osanai CH. A organização do espaço e os processos endêmicos epidêmicos. In: Leal MC, Sabroza PC, Rodrigues RH, Buss PM, ( orgs) Saúde, Ambiente e Desenvolvimento, Rio de Janeiro: ABRASCO/São Paulo: Hucitec 2: 57-77, 1992.

15. Schatzmayr HG. Dengue situation in Brazil by year 2000. Memórias do Instituto Oswaldo Cruz 95:179-181, 2000.

16. Secretaria Municipal de Saúde do Rio de Janeiro, Serviço de Saúde Coletiva, Coordenação de Programas de Epidemiologia. Relatório de Dengue no Município do Rio de Janeiro. Casos de Denque por Mês e Tipo http:// www.saude.rio.rj.gov.br acessado em 12/4/2002.

17. Secretaria Municipal de Saúde do Rio de Janeiro, Serviço de Saúde Coletiva Coordenação de Programas de Epidemiologia. Relatório de Dengue no Município do Rio de Janeiro. Casos de Dengue por Mês e Evolução. http:/ /www.saude.rio.rj.gov.br, acessado em 12/4/2002.

18. Tauil PL. Aspectos críticos do controle do dengue no Brasil. Cadernos de Saúde Pública 18: 867-871, 2002. 